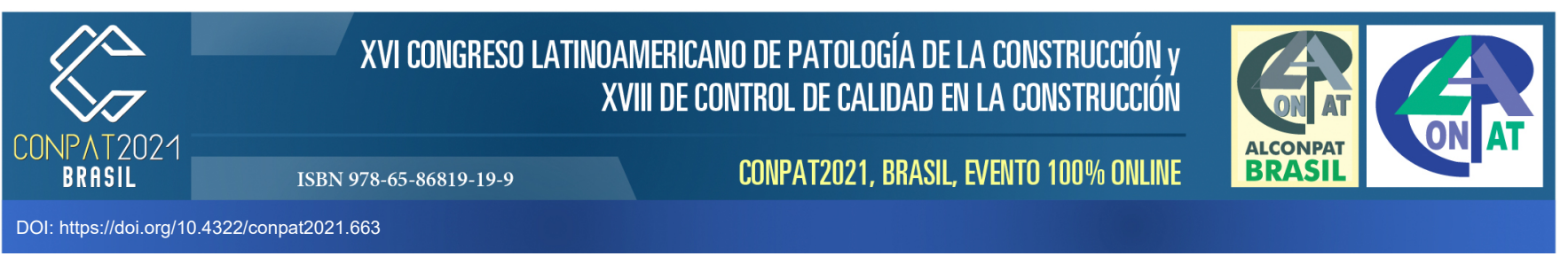

\title{
ANÁLISE DAS MANIFESTAÇÕES PATOLÓGICAS NO CONDOMÍNIO ROGACIANO LEITE NA CIDADE DE FORTALEZA
}

\author{
J. C. Sales ${ }^{1 *}$ \\ *email: juscelinochaves@hotmail.com \\ ${ }^{1}$ Departamento de Engenharia Civil, Universidade Estadual Vale do Acaraú, Sobral, Brasil
}

\section{RESUMO}

O presente trabalho faz uma análise das manifestações patológicas em edifícios de um condômino residencial Rogaciano Leite na cidade de Fortaleza no estado do Ceará. Para a realização desse trabalho foram feitas visitas in loco as edificações onde foi feita uma inspeção visual, como também foi feito um acompanhamento da recuperação de pilares que estavam comprometidos pela corrosão da armadura em pilares e vigas. Dentre as manifestações patológicas encontradas foram a corrosão da armadura, umidade, destacamento da pintura, destacamento da argamassa, bolo, fissuras, corrosão em tubulação de gás (GLP) e em portão etc. Foi possível concluir que as edificações apresentaram várias patologias que foram feitas a sua recuperação e que o aumento da corrosão das armaduras decorre principalmente do efeito da carbonatação do concreto devido ao grande aumento do fluxo de veículos no entorno das edificações emitindo $\mathrm{CO}_{2}$ como também a espessura do cobrimento menor do que o especificado na norma técnica.

Palavras-chave: edifícios, manifestações patológicas, corrosão na armadura, condômino Rogaciano Leite. 
The present work analyzes the pathological manifestations in buildings belonging to a residential condominium Rogaciano Leite in the city of Fortaleza, in the state of Ceará. To carry out this work, on-site visits were made to the buildings, where a visual inspection was carried out, as well as monitoring the recovery of columns that were compromised by corrosion of the reinforcement in columns and beams. Among the pathological manifestations found were corrosion of the armor, moisture, detachment of paint, detachment of mortar, cake, cracks, corrosion in gas pipes (LPG) and in gates, etc. It was possible to conclude that the buildings presented several pathologies that were made their recovery and that the increase in corrosion of the reinforcement is mainly because of the carbonation of the concrete due to the large increase in the flow of vehicles around the buildings emitting $\mathrm{CO}_{2}$ as well as the thickness of the coverage less than specified in the technical standard.

Keywords: buildings, pathological manifestations, reinforcement corrosion, condominium Rogaciano Leite.

\section{INTRODUÇÃO}


Muitas edificações em todo o mundo são feitas com concreto armado como os edifícios do Condomínio Rogaciano Leite na cidade de Fortaleza e ao longo de sua vida útil vão aparecendo as manifestações patológicas.

A construção civil é uma ciência comum desde a antiguidade e vem se modificando com o passar do tempo, sobretudo no que diz respeito às novas técnicas construtivas e materiais utilizados. Porém, mesmo com os avanços na construção, é notável o grande número de residências com manifestações patológicas construtivas, podendo aparecer logo após a construção ou durante a vida útil da residência (Andrade, 2020).

A carbonatação é causada pela penetração de agentes agressivos no concreto através dos poros/aberturas, como o gás carbônico $\left(\mathrm{CO}_{2}\right)$, que se dilui na umidade presente na estrutura, formando o ácido carbônico $\left(\mathrm{H}_{2} \mathrm{CO}_{3}\right)$ (Carvalho, 2020).

Corrosão do aço em concreto armado é a causa mais comum de degradação. O aço é atualmente protegido pela alta alcalinidade da estrutura. No entanto esse estado passivo pode ser rompido pela ação de íons agressivos, iniciando o processo corrosivo (Neri, 2013).

Infiltrações normalmente são causadas por falta de impermeabilização ou elementos danificados, como telhas quebradas. Esse tipo de patologia também pode ocorrer devido a falhas nas instalações hidráulicas, como rompimento da tubulação ou vedação comprometida; ou até mesmo por mal planejamento da tubulação de aviso e extravasão da caixa d'água (Carvalho, 2020).

Acreditava-se, antigamente, que o concreto armado era um material eterno, uma vez que apresentava um ótimo comportamento perante o uso e a exposição ao ambiente. Hoje, sabe-se que não é assim (Bolina, 2019).

Pesquisadores concluíram que algumas ocorrências de patologia construtiva nos postos de saúde da cidade de Criciúma no Estado de Santa Catarina, se devem sobretudo à falta de manutenção periódica, bem como vícios construtivos. A umidade é a patologia mais encontrada, e evidencia que quando a manutenção é inexistente desencadeia outras anomalias (Nazario, 2011).

O dióxido de carbono presente na atmosfera ao penetrar através dos microporos do concreto atinge lenta e gradativamente pequenas profundidades medidas a partir da superfície. A frente de carbonatação então formada, dependendo da capa de cobrimento poderá atingir o nível da armadura. A massa de concreto carbonatada reduz o pH do valor original situado entre 12,7 e 13,8 para valores situados entre 8 e 9 . Diante das novas condições resultante do $\mathrm{pH}$ o filme que envolve a armadura será atingido por barras despassivadas (Oliveira, 2013).

Através da análise das alternativas de intervenção propostas para cada sistema construtivo que apresentou manifestações patológicas na edificação, gerou-se uma sequência seguindo uma ordem de importância para realização dos reparos conforme o nível dos agravos, atribuições estruturais do elemento danificado, ação contínua das causas geradoras sobre as manifestações patológicas existentes, facilidade na execução dos reparos, disponibilidade de ferramentas e materiais necessários na região onde se encontra o edifício (Zuchetti, 2015).

Sales (2021) detectou a existência da manifestação patológica da corrosão de armadura na Igreja de Santa Edwirges na cidade de Fortaleza no Estado do Ceará no Brasil decorrente da existência de carbonatação e íons cloretos.

A região amazônica tem um clima úmido e tropical (com clima equatorial), onde há muita incidências de chuvas, essas ocorrências patológicas de umidade nas edificações são maiores. Isso também favorece para o desenvolvimento de fungos, porque a própria umidade do ar ajuda no aparecimento dessas anomalias. Então esses cuidados na elaboração do projeto, impermeabilização, e na manutenção preventiva, tende a ser mais criterioso (Machado, 2021).

A corrosão dos aços tem sido umas das principais manifestações patológicas nas estruturas de concreto armado, trazendo grandes danos e prejuízos. Devido a isso, deve-se entender este processo por completo para impedir sua ocorrência, ou ao restaurar elementos estruturais atacados, evitar que depois de curados, não sofram novamente esta anomalia. Com o surgimento da oxidação, 
haverá uma expansão da armadura, de modo que o concreto sofrerá fissuração e terá sua aderência reduzida com o aço (Trindade, 2015).

O presente trabalho teve objetivo analisar as manifestações patológicas existentes em dois blocos de apartamentos existentes em fortaleza e mostrar a recuperação de pilares de sustentação de um dos blocos da edificação.

\section{METODOLOGIA}

Para a realização desse trabalho foram feitas visitas in loco as edificações onde foi feita uma inspeção visual, como também foi feito um acompanhamento da recuperação de pilares que estavam comprometidos pela corrosão da armadura em pilares e vigas. Foram feitos registros fotográficos dos dois prédios que compõem o Condomínio Rogaciano Leite.

\section{AS MANIFESTAÇões PATOLÓGICAS NO CONDOMÍNIO ROGACIANO LEITE}

Os edifícios que foram analisados estão localizados na Rua Socorro Azevedo número 150 no Bairro Luciano Cavalcante da cidade de Fortaleza no Estado do Ceará. O Condomínio Rogaciano Leite é composto de dois blocos de apartamentos com cada bloco possuindo 24 apartamentos e possuindo quatro pavimentos sem contar o térreo, ou seja, possuem quatro andares. As edificações foram construídas a mais de 30 anos em um bairro residencial que tinha pouco movimento de veículos e uma área ainda não habitada no entorno do bairro. Cada apartamento possui $82 \mathrm{~m}^{2}$ de área.

As manifestações patológicas aparecem devido à baixa qualidade no projeto, os materiais de baixa qualidade utilizados, a execução com algumas falhas e a falta de manutenção ao longo da vida útil da edificação.

Em março de 2021 as colunas (pilares) do edifício foram pintadas só com a massa e a tinta e quando deu a primeira chuva que molhou os pilares soltou tanto a massa como a tinta.

Para fazer correto o pintor aplicou o selador, para depois aplicar a massa acrílica e em seguida colocar a tinta.

A massa corrida pode ser riscada e dissolve com a água e só é usada em ambiente interno. Já a massa acrílica não dissolve com a água e nem risca. O selador serve como uma resina e é possível perceber que quando ele é passado sobre as telhas ela deixa a telha brilhosa.

Devido ao vazamento ocasionado por uma fissura na tubulação de água, acarretou uma grande umidade na parede (vedação) do edifício, onde foi necessário quebrar a alvenaria para retira o vazamento que ocorreu em um dos banheiros de um apartamento conforme mostra a Figural. 


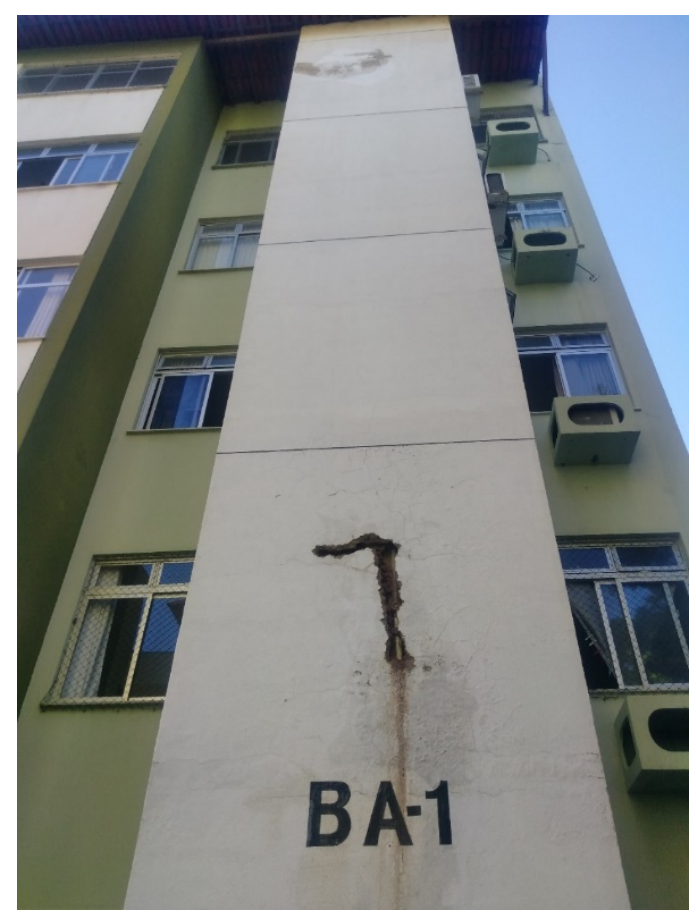

Figura 1. Fissura na tubulação de água, acarretou uma grande umidade na parede (vedação). Fonte: própria, 2019.

Para a recuperação e retirada da manifestação patológica da umidade ocasionada pelo vazamento da tubulação da instalação hidráulica foi primeiramente tirado o vazamento na parede do banheiro externamente e posteriormente foi feito um novo reboco na área em que foi quebrada a parede para a retirada do vazamento e posteriormente seria feita a pintura da parede (Figura 2).

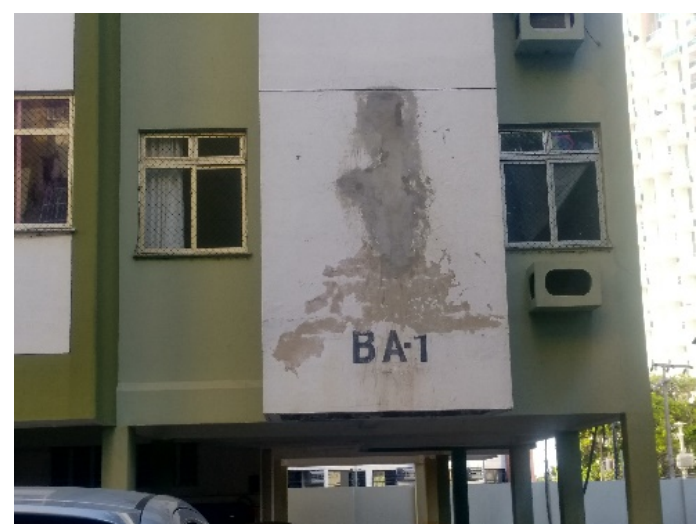

Figura 2. Recuperação e retirada da manifestação patológica da umidade ocasionada pelo vazamento da tubulação. Fonte: própria, 2019.

Na Figura 3 é possível perceber o destacamento da pintura de revestimento da fachada externa do edifício. O destacamento ocorreu principalmente na parede de banheiros de um dos blocos de apartamento. Também foi possível perceber a existência de bolor nas paredes da fachada do edifício externamente. 


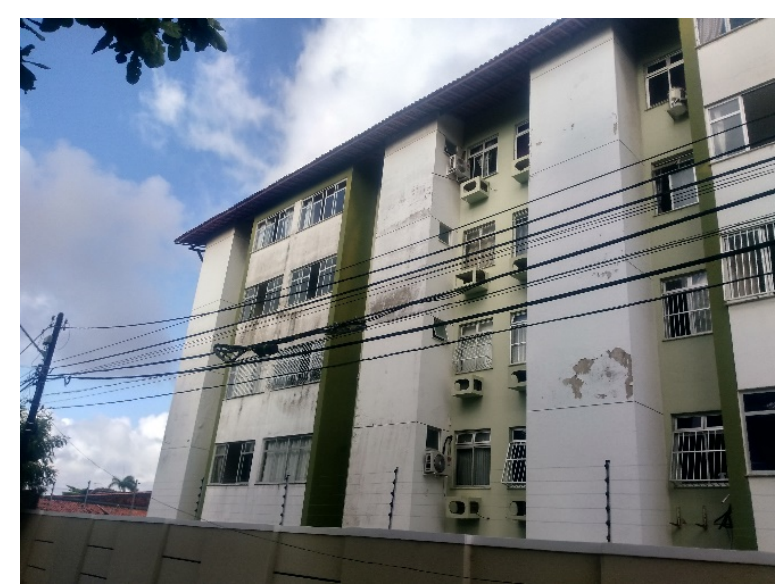

Figura 3. Destacamento da pintura de revestimento da fachada externa. Fonte: própria, 2019.

A Figura 4 mostra a umidade no quarto andar em uma parede externa, que foi a manifestação patológica mais encontrada nos dois blocos de edifícios analisados. Quando foi construído não existiam nenhum edifício próximo da construção, porém com o passar dos anos foram construídos edifícios bem mais altos na vizinhança da edificação.

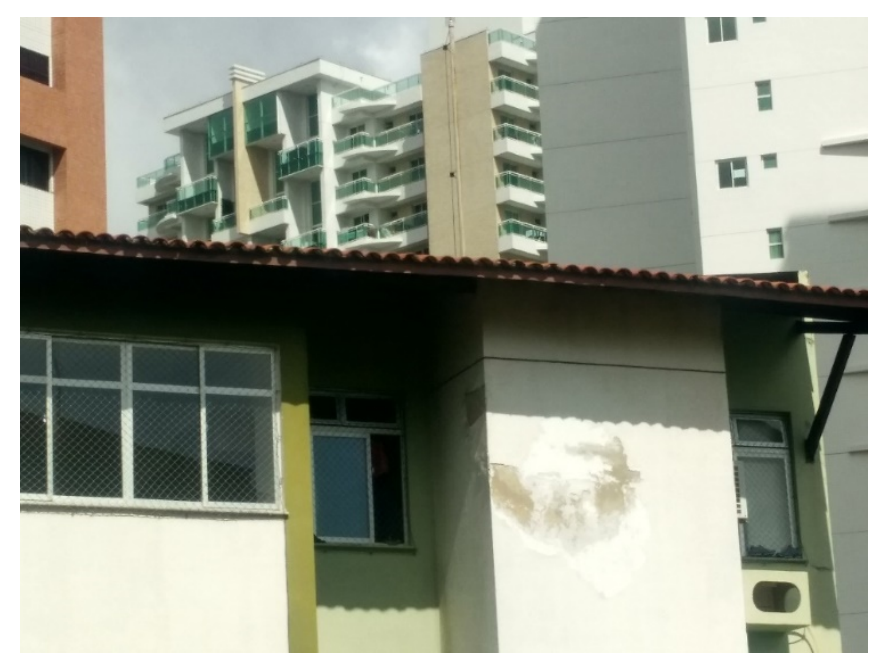

Figura 4. Umidade no quarto andar em uma parede externa. Fonte: própria, 2019.

A Figura 5 mostra corrosão nos vergalhões dos combogós feito de concreto que foram colocados para melhorar o conforto térmico dentro das áreas internas dos edifícios, como é o caso do acesso aos apartamentos. Foi possível perceber também que existem combogós trincados onde posteriormente o destacamento do concreto e o vergalhão ficará exposto acelerando assim o processo corrosivo do aço. 


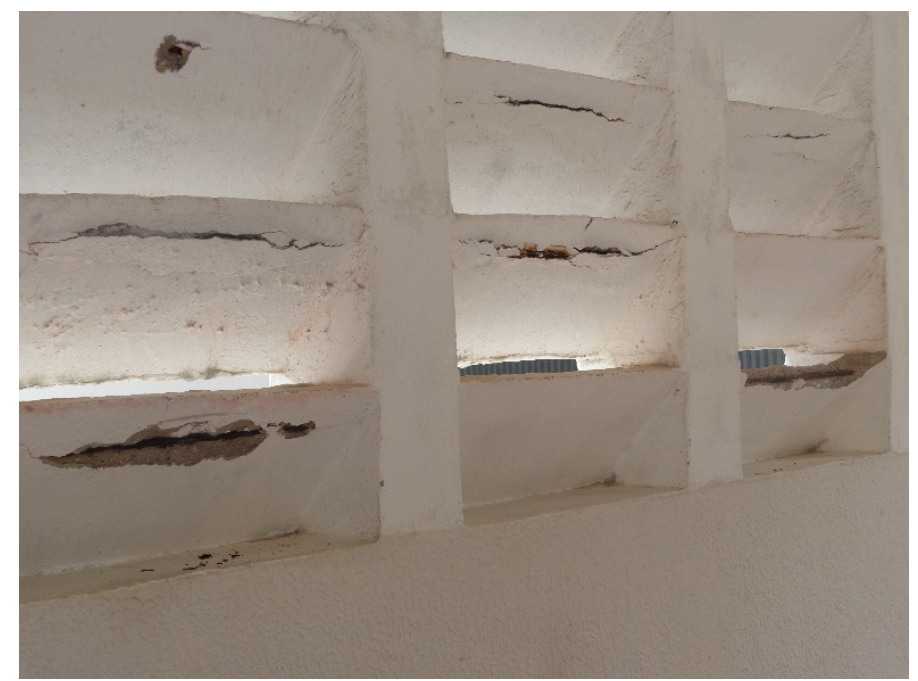

Figura 5. Corrosão nos vergalhões dos combogós feito de concreto. Fonte: própria, 2020.

Foi possível perceber a ocorrência de corrosão na armadura em pilares e vigas de concreto armado. $\mathrm{O}$ aumento da corrosão das armaduras decorre principalmente do efeito da carbonatação do concreto devido ao grande aumento do fluxo de veículos no entorno das edificações emitindo $\mathrm{CO}_{2}$ como também a espessura do cobrimento menor do que o especificado na norma técnica. Devido a corrosão da armadura ocorreu o esmagamento do concreto que gerou trincas no pilar e posterior destacamento do cobrimento da armadura (Figura 6).

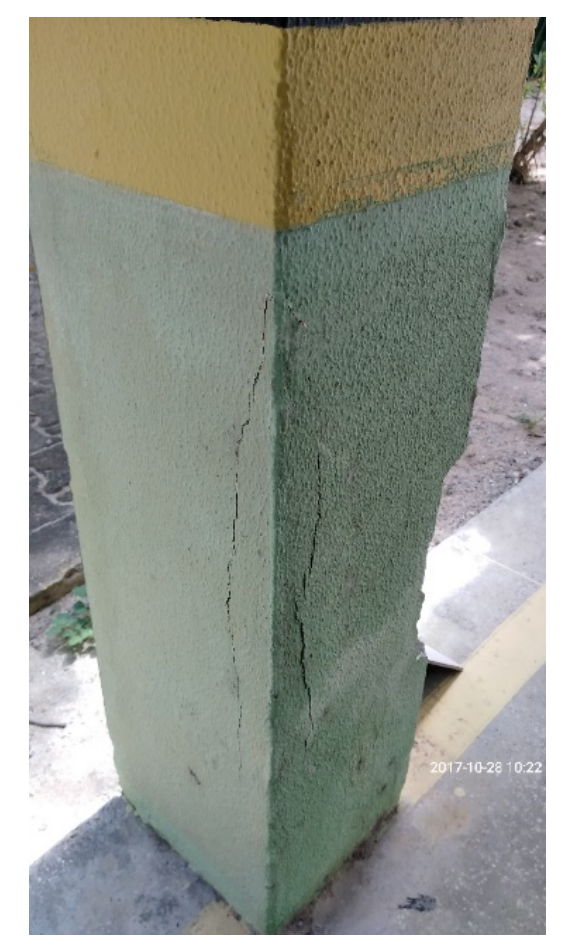

Figura 6. Esmagamento do concreto que gerou trincas no pilar. Fonte: própria, 2019.

A Figura 7 mostra corrosão na armadura em um pilar de concreto armado onde é possível perceber também a trinca vertical seguindo a mesma direção do vergalhão dos dois lados do pilar. $\mathrm{O}$ vergalhão já se encontra bastante oxidado (com ferrugem) com acelerado processo corrosivo. Como consequência da corrosão da armadura ocorreu o esmagamento do concreto. A corrosão da 
armadura ocorreu devido a presença do dióxido de carbono, ou seja, devido a carbonatação do concreto.

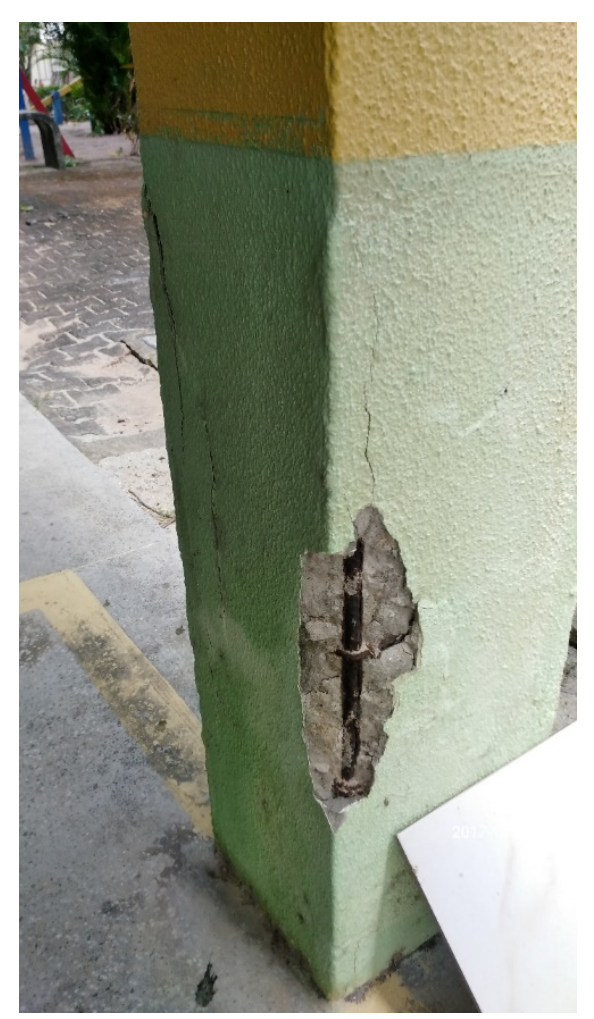

Figura 7. Corrosão na armadura em um pilar de concreto armado. Fonte: própria, 2019.

Como profilaxia para reparar os efeitos da carbonatação e fazer a recuperação dos pilares que estavam com corrosão na armadura foi utilizado o método de reparo convencional, onde foi destacado todo o cobrimento que estava sobre as armaduras corroídas principalmente devido a carbonatação do concreto, depois foi passado a escova de ação sobre os vergalhões corroídos para retirar toda a ferrugem posteriormente foi passada a tinta de cor verde (pintura de proteção superficial) à base de ferrolack óxido para fazer a proteção por barreira na armadura evitando o ataque o oxigênio (Figuras 8 do lado esquerdo e Figura 9 do lado direito). Foi possível perceber o agregado graúdo do concreto do pilar é que o lado direito do pilar estava bem mais comprometido com a corrosão da armadura do que o lado esquerdo do pilar. Sabe-se que a carbonatação é a penetração do $\mathrm{CO}_{2}$ nos poros do concreto. 


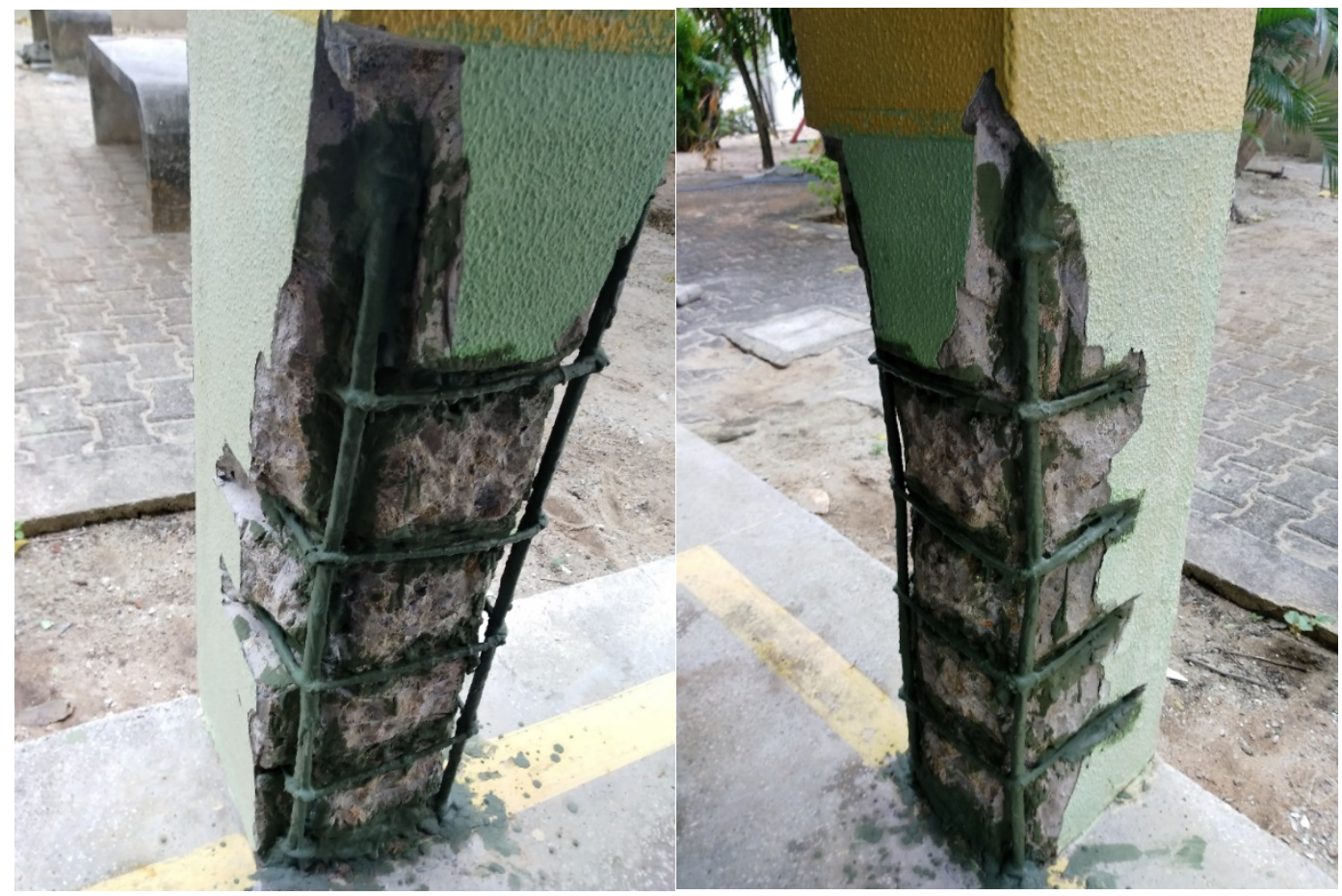

Figura 8. Recuperação dos pilar lado esquerdo. Figura 9. Recuperação dos pilar lado direito.

Fonte: própria, 2019.

Na Figura 10 foi possível perceber o pilar recuperado depois que ele foi concretado, ou seja, colocado um novo cobrimento e posteriormente o pilar seria pintado.

Foi utilizado o processo convencional de recuperação de armadura corroídas em estruturas de concreto armado.

No Estado do Ceará localizado no nordeste do Brasil se usa muito pouco a técnica de realcalinização (eletroquímica, química ou passiva) para se recuperar estruturas de concreto armado com corrosão na armadura, onde sabe-se que a partir dos anos de 1980 essa técnica já é utilizada.

Houve um erro na confecção do pilar pois não foi seguida corretamente a espessura do cobrimento que ficou menor que que é especificado na norma técnica.

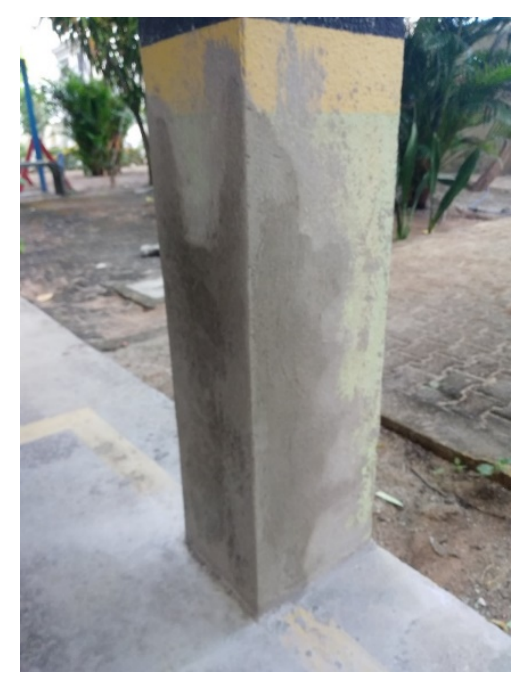

Figura 10. Pilar recuperado pelo método convencional. Fonte: própria, 2019. 
A Figura 11 mostra o pilar com destacamento da pintura e de pequena quantidade de concreto, onde é possível também percebera umidade na base do pilar e no piso de concreto.

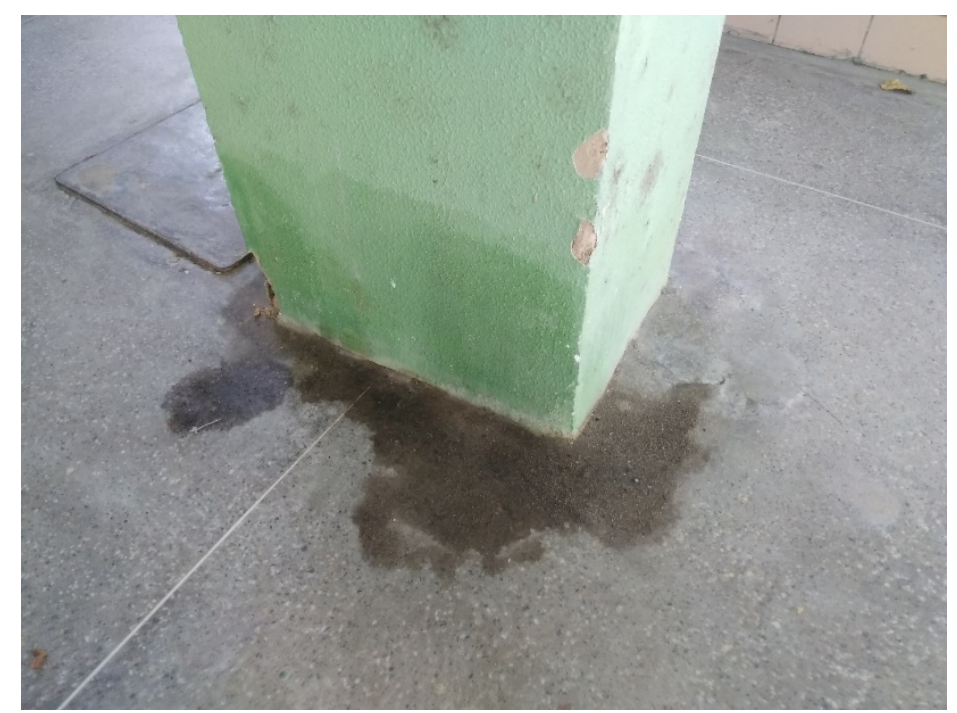

Figura 11. Pilar com destacamento da pintura e de pequena quantidade de concreto. Fonte: própria, 2019.

Além dos pilares foi possível encontrar corrosão na armadura de uma viga de concreto armado, onde a armadura está exposta é um pequeno ponto despois do destacamento do concreto. Também parte do estribo já está exposto com o destacamento do concreto (Figura12).

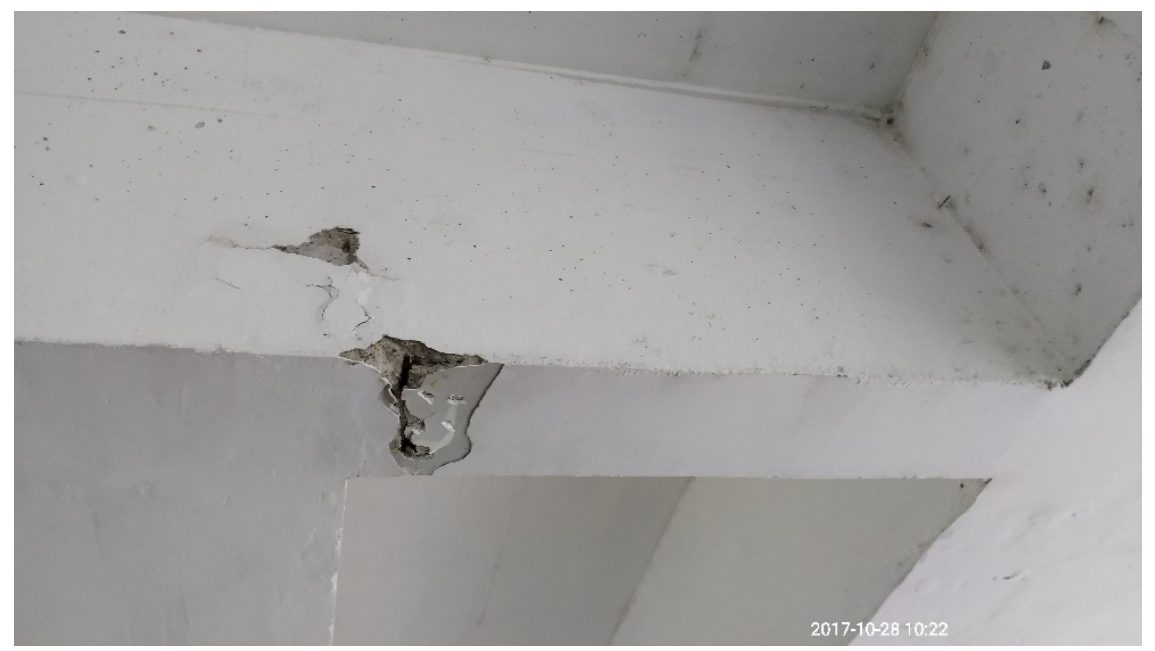

Figura 12. Corrosão na armadura de uma viga de concreto armado. Fonte: própria, 2017.

A Figura 13 mostra a corrosão da tubulação de gás GLP (Gás Liquefeito de Petróleo) em acelerado processo de corrosão (ferrugem) como também o portão que dar acesso ao local onde se coloca o botijão de gás que foi construído com o vergalhão corrugado de aço CA-50 utilizado para confeccionar pilares e vigas de concreto armado com pontos de corrosão, sendo o ferrolho a parte que está mais corroída. 


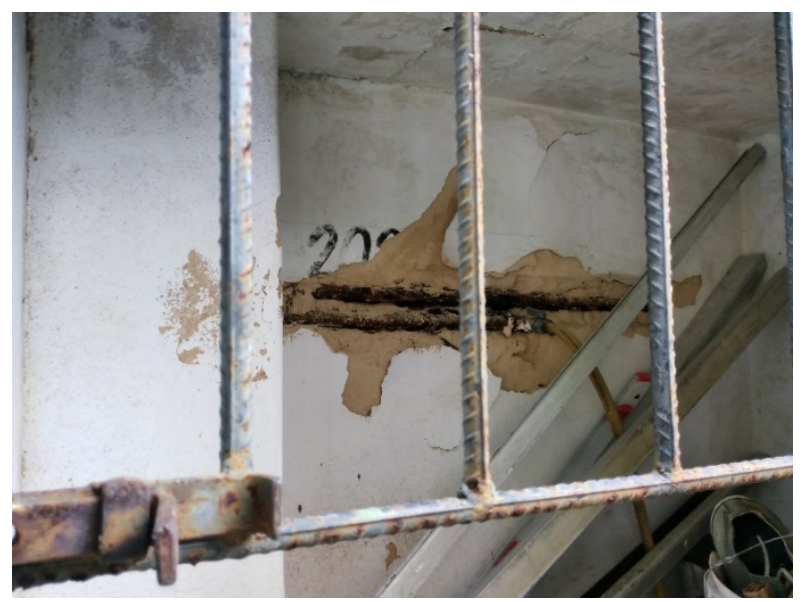

Figura 13. Corrosão da tubulação de gás GLP (Gás Liquefeito de Petróleo). Fonte: própria, 2018.

Os revestimentos, principalmente das fachadas são verdadeiros formadores da imagem do imóvel. O declínio funcional do revestimento provocado pelo surgimento de uma manifestação patológica, soma-se um prejuízo de natureza estética e simbólica, causado pela deterioração visual da edificação (Segat, 2006).

A Figura 14 mostra o destacamento da pintura e o desplacamento da argamassa de uma parede próximo ao piso feito de cerâmica esmaltada. Também foi possível perceber a caixa de passagem da fiação elétrica feita de aço com acelerado processo de corrosão, valendo ressaltar que as caixas eram feitas de aço devido a edificação ser antiga.

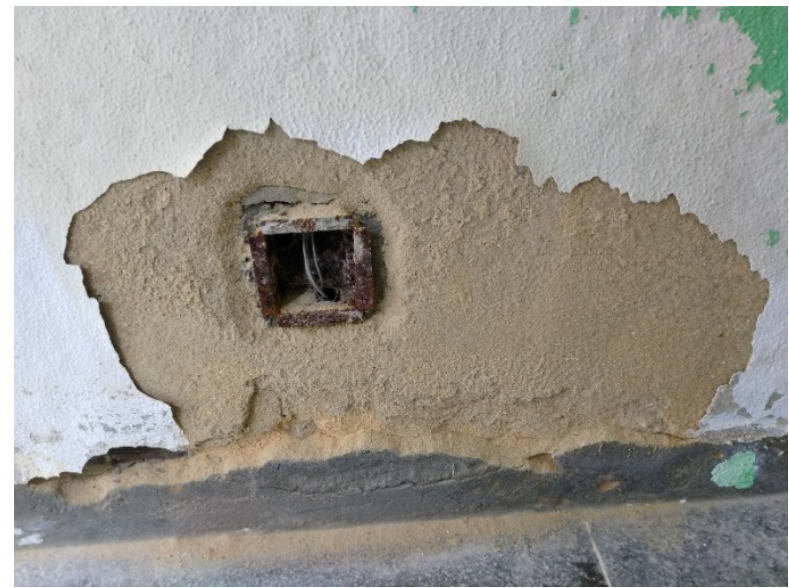

Figura 14. Destacamento da pintura e o desplacamento da argamassa de uma parede. Fonte: própria, 2018.

Cada bloco de apartamento possui o aterramento do para raio. O aterramento está localizado abaixo de um piso feito de concreto e fica próximo a saída da água pluvial que é drenada por uma tubulação de PVC. O piso de concreto apresenta rachaduras inclusive onde está a ponta da haste de aterramento de cobre e está nascendo vegetação próxima a tubulação de água e a parede. Foi possível perceber também a existência de bolor na parede do lado direito da tubulação e destacamento da tinta da parede do lado esquerdo com fissuras no reboco (Figura 15). 


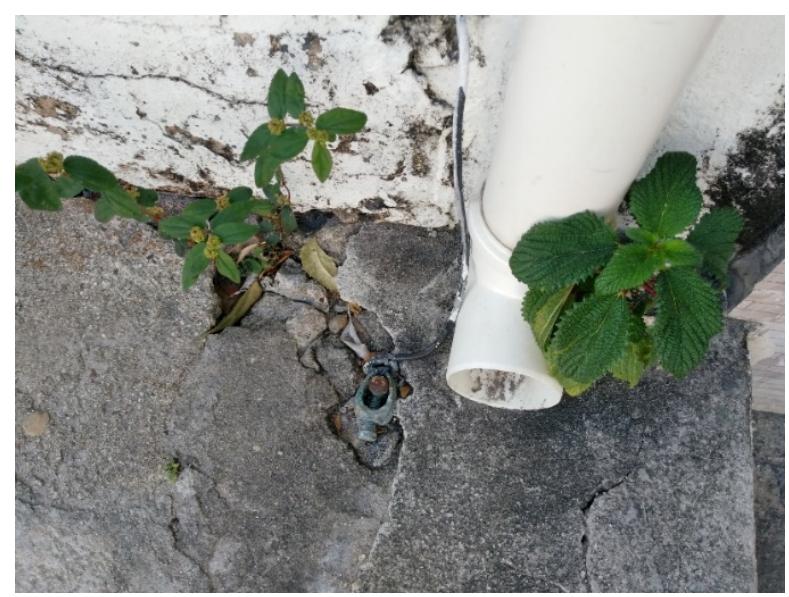

Figura 15. Bolor na parede do lado direito da tubulação e destacamento da tinta da parede. Fonte: própria, 2019.

Foi possível perceber na Figura 16 a existência da manifestação patológica destacamento da pintura, como também bolor na base de um dos pilares devido a umidade em uma das edificações do Condomínio Rogaciano Leite.

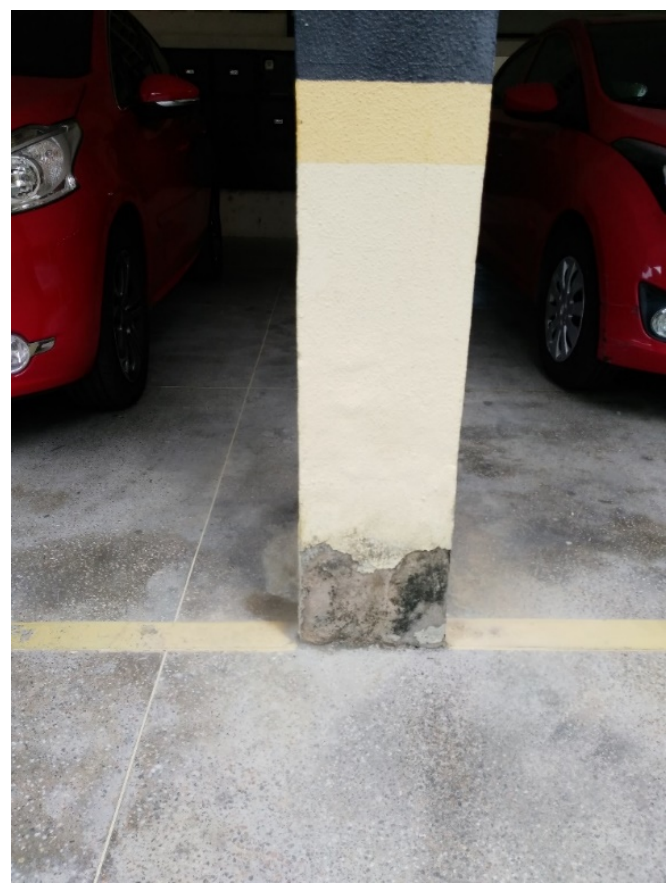

Figura 16. Destacamento da pintura, como também bolor na base de um dos pilares devido a umidade. Fonte: própria, 2019.

\section{CONCLUSÃO}

Dentre as manifestações patológicas encontradas foram: a corrosão da armadura, umidade, destacamento da pintura, destacamento da argamassa, bolo, fissuras, corrosão em tubulação de gás (GLP) e em portão etc.

Os dois edifícios apresentaram várias manifestações patológicas onde vem sendo feita a profilaxia ao longo dos anos. 
No Bairro Luciano Cavalcante onde está localizado o Condomínio Rogaciano Leite ao longo dos anos vem aumentando muito a construção de novos edifícios e acarretando o aumento da população, e com isso aumentou sensivelmente o trânsito de veículos passando no entorno do condomínio, que fica localizado em uma esquina. A liberação do $\mathrm{CO}_{2}$ do escapamento dos veículos acelerou a carbonatação do concreto armado dos edifícios.

\section{REFERÊNCIAS}

Andrade, P. R. S.; Silva, L. B.; Sotero, C. S. (2020). "Estudo de patologias em uma residência térrea". Revista Científica Multidisciplinar Núcleo do Conhecimento. ano 05, ed. 10, vol. 17, pp. 158-172. 2448-0959. ISSN: Disponível em: $<$ https://www.nucleodoconhecimento.com.br/engenharia-civil/residencia-terrea $>$. Acesso em: 07 mai. 2021.

Bolina, F. C.; Tutikian, B. F.; Helene, P. R. L. (2019). "Patologia das Estruturas". Editora Oficina de Textos, São Paulo.

Carvalho, M. (2020). "Patologias na Construção Civil - Tipos e Causas". Disponível em: $<$ https://carluc.com.br/manutencao-predial/patologias-na-construcao-civil/>. Acesso em: 07 mai. 2021.

Machado, K. M.; Alencar, E. A. B. (2021). "Levantamento de patologia causadas por umidade nas edificações na cidade de Manaus - AM'. Disponível em: < https://semanaacademica.org.br/system/files/artigos/artigo_1_8.pdf>. Acesso em: 12 ago. 2021.

Nazario, D.; Zacan, E. C. (2011). "Manifestações das patologias construtivas nas edificações públicas da rede municipal de Criciúma: Inspeção dos sete postos de saúde". UNESC Universidade do Extremo Sul Catarinense.

Neri, K. ; Alves, H.; Ferreira, P.; Meira, G.; Vilar, E. (2013). “Avaliação de estruturas concretas submetidas ao ataque de cloreto de sódio e ácido sulfúrico". $55^{\circ}$ Congresso Brasileiro do Concreto. Gramado.

Oliveira, R.; Zarzar Junior, F.; Bittencourt, T. (2013). "Estimação probabilística da vida útil de componentes estruturais de pontes submetidas a carbonatação". 55 Congresso Brasileiro do Concreto. Gramado.

Sales, J. C. (2021). “Análise das manifestações patológicas na igreja de Santa Edwirges na cidade de Fortaleza no Estado do Ceará no Brasil”. XVII Congreso International sobre Patologiay and Rehabilitation de la Construcciones. CINPAR. online.

Segat, G. T. (2006). "Manifestações patológicas em revestimentos de argamassa: um estudo do caso em um conjunto habitacional popular na cidade de Caxias do Sul (RS) ”. Dissertação (Metrado Profissionalizante). Universidade Federal do Rio Grande do Sul. Porto Alegre.

Trindade, D. S. (2015). "Patologia de estruturas de concreto armado". Trabalho de Conclusão de Curso, Curso de Graduação em Engenharia Civil, Universidade Federal de Santa Maria. Santa Maria 
Zuchetti, P. A. B. (2015). "Patologias da construção civil: investigação patológica em edificio corporativo de administração pública no Vale do Taquari/RS". 2015. Monografia (Graduação em Engenharia Civil). Universidade do Vale do Taquari. UNIVATES, Lajeado. Disponível em: $<$ http://hdl.handle.net/10737/939>. Acesso em: 27 mai. 2021. 